\title{
Conceptions Of Learning: An Exploratory Study In The Context Of Marketing Students
}

Ulku Yuksel, (E-mail: u.yuksel@econ.usyd.edu.au ), University of Sydney, Australia

Catherine Sutton-Brady, (E-mail: c.sutton-brady@econ.usyd.edu.au), University of Sydney, Australia

\begin{abstract}
This study investigates marketing three phenomena. First authors examine student's approaches to studying and learning, then they explore their conceptions of learning, and they finally delve into teacher's perceptions of student's learning. Authors recast the conceptions of learning literature in which they classify simplifiers, accountants, utilitarians, curious, philosophers, and finally intellectuals. Results indicate that the categorization of student's conceptions and approaches to learning appears to be internally consistent. Authors additionally propose a conceptual model according to the results of their qualitative research indicating the relationship between students' conceptions of learning and their approaches to studying.
\end{abstract}

\section{INTRODUCTION}

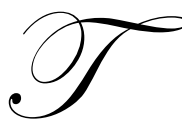

his study is about student's approaches to studying and learning, their conceptions of learning, and teacher's perceptions of student's learning. The theoretical base for this study is from the constructive and valuable literature about student's approaches to learning (Case and Gunstone, 2003, p. 55; Mann, 2003, p. 7; Marton and Säljö 1976; Ramsden, 2003, p. 41, 45), conceptions of learning (Marton, Dall'Alba and Beaty, 1993; Marton, Watkins and Tang, 1995; Ramsden, 2003, p.40), and teacher's perceptions on teaching and student learning (Brookfield, 1995, pp. 28-39). According to our results from the student interviews we have developed a conceptual model indicating the relationship between students' conceptions of learning and their approaches to studying. This is important because it builds on the available literature and elucidates that even basic categories of conceptions may lead to the broadened approaches to studying and learning. Results also indicate that approaches to learning triggered by other antecedents of approaches, such as personality traits, motivation levels may lead to higher categorizations in conceptions of learning.

This study is organized as follows. First, we present a literature review on notions comprising of student approaches to studying and learning and on conceptions of learning. Then we present our research including the context of our research, examples of some interviews and results. Next we discuss our findings and propose a conceptual model. Finally, we conclude with some recommendations for all educators.

\section{STUDENT APPROACHES TO STUDYING AND LEARNING}

An approach to studying indicates the way a student distinguishes his/her learning efforts in relation to the students' experience with the course (unit of study) or the topic and the course's structure and organization (Ramsden, 2003, pp.41-45). There are two fundamental student approaches to studying and learning in terms of depth of learning in the literature. The first one is the surface approach and the second one the deep approach. Marton, Watkins, and Tang (1997) have proposed this general framework. They construct varied conceptions of learning along these two dimensions, that is, a temporal dimension (acquiring-knowing-applying) and depth of learning (surface-deep) (Marton, Wen, Nagle, 1996).

To be able to understand which approach the students are taking, lecturers have to know how students decide and manage what to learn and know how they decide and manage how to learn. Students who apply a surface approach to learning memorize and try to remember and recall things, which they might get tested on. They are exam 
and assessment-oriented. They focus on external requirements, treating tasks as external imposition (Mann, 2003, p. 7; Ramsden 2003, p.41). They display a lack of an intention to understand what they learn (Case and Gunstone, 2003, p. 55). On the other hand, students who apply a deep approach to learning do not necessarily always try to recall things from their memory for the exams. They usually think, compare and probe the information given to understand (Case and Gunstone, 2003, p. 55) the real meaning and scope of it. And they look at how this new information relates to what they already knew (knowledge). Their reasons for their learning are not to pass the exams or to receive high marks in exams only but rather to increase their knowledge and satisfy their curiosity. They are inquisitive students and question what they learn.

\section{CONCEPTIONS OF LEARNING}

A conception of learning is about how an individual considers learning, that is, how one makes sense of learning (Ramsden, 2003, p.40). Students have different conceptions of learning. Some of them perceive learning as an increase of knowledge (category 1). We will refer to this kind of learning as learning for enlarging common knowledge or common wisdom, and categorize such learners as "simplifiers" in our model (figure 1) They like simple things. For them, simple equals logical, comprehensible and usable; simple equals safe. The Pocket Oxford Dictionary defines simple as "easily understood or done, presenting no difficulty; nor complicated or elaborate". The main motive of such a conception is that they are interested in what they learn and they want to accumulate information. Simplifiers learn because they would like to simplify their lives by broadening their knowledge. They are passive and/or sometimes active learners, that is, they put effort into learn.

The second group conceives learning as memorizing (category 2). We call them "accountants" because they are very calculative in their conscious or unconscious reasoning of learning. They learn only to survive. They will then use what they have learnt in compulsory situations and desperate circumstances, such as passing an exam, finding a job, making an impression, or promoting in their career. These people memorize what the teachers say or what is in the book with no transformation from what they receive. Their only job is to remember what is said or written.

The third group regards learning as the acquisition of facts, procedures or skills, which are retained and utilised in practice (category 3). I call them "utilitarian". Utilitarians believe that they should store away the information and when they need to do something they can get the procedure or the information out and use it. However, the retrieved information is exactly the same as what was put in by the teacher or the book. There is little or no transformation of the information by the students. They believe that they have learnt something when they can remember how to do it. They are able replicate it at a later date just as the teacher has told, them, they have heard in the media or have read it from a book.

"These first three groups have a view of knowledge as something given; something that exists "out there", waiting to be picked up, taken in and stored. This is conceptually linked to a view of learning as a passive experience, consisting of receiving and absorbing knowledge transmitted by the teacher "(Akerlind and Trevitt, 1995, p.2).

The fourth group conceives learning as understanding (category 4). We refer to them as "curious". Specifically, they perceive learning as the process of making sense of (understanding) things - abstracting meaning from them. Learning is an effort they make themselves. They learn and are able to explain it later to someone else.

The fifth group conceives learning as the process of making sense of reality (category 5). These we call "philosophers". For these philosophers learning is seen as a very personal thing. Learning is not just about understanding what others mean, but about making sense of their own world. Explicitly, when they believe that they have really understood something, it changes the way they see things and their reality becomes different. The novel knowledge and the new understanding, comprehension or insight makes them look at themselves and others in a different way. This awareness is not just learning so that they can knock off an essay but learning to change them and their perceptions and views of the world.

The final group conceives learning as the process of changing as a person (Marton, Dall'Alba and Beaty, 1993) and changing their environment accordingly (category 6). We call them "intellectuals". Intellectuals 
(particularly public intellectuals) go beyond philosophers as they seek to scrutinize an aspect of the world that is consistent with a personal and activist stance - bringing into view an entirely new way of conceiving something.

These three groups (category 4, 5, and 6) highlight the significance of comprehending, making sense of and receiving and adding up sense from knowledge. This is conceptually an active approach to learning because the student makes his/her own efforts to construct and produce individual sense from knowledge and ideas (Akerlind and Trevitt, 1995; Ramsden, 1992, 2003).

In summary, there are six conceptions of learning: increasing one's knowledge, memorizing and reproducing, applying, understanding, seeing something in a different way, and changing as a person. There is a separation between these conceptions in which the first three are rather passive and the last three rather active in learning.

\section{CONTEXT OF RESEARCH}

This study is exploratory and descriptive in nature. For the study's purpose, we have conducted personal face-to-face interviews with the students. These interviews were recorded for ease of transcription. The students involved in these interviews are from the Marketing Principles classes, a large postgraduate subject (160 students) offered by the Faculty of Economics and Business, School of Business, Discipline of Marketing at the University of Sydney. Marketing Principles is a compulsory course for students taking a marketing major, but can also be taken as an elective in various degrees although the majority of students are from Economics and Commerce. There are no prerequisites for enrolling in this course within the university. For this paper we have interviewed seventeen students enrolled in the Faculty of Economics and Business, School of Business, Discipline of Marketing at the University of Sydney who are taking a marketing major. We discontinued interviewing further as there were enough replications on the conceptions of learning and learning approaches in this sample of students. For this paper outline and give examples of three interviews, since they were distinct, interesting, and very relevant in interpreting the conceptions of learning and student's approaches to learning. Based on the student interviews and available literature we develop a conceptual framework and model.

\section{INTERVIEWS}

Our first selected participant was Sandy. In terms of the decision on what to learn and how to learn she mostly relies on what the lecturer mentions as important (Baderin, 2003, p.109; Brookfield, 1995, p.36). We have observed this attitude toward what to learn with all participants as a sign of surface approach to learning. However, they differed in their opinion after going into detail with the interview. Sandy said, for example, that she only selects subjects, which she really likes and considers important for her career. She would like to work in an advertising agency when she graduates from the university. Even though she is partly limited with her lecturer's views on what to learn, she always relates what she learns with daily-life examples in advertising and commercials. She compares theory with application, to be able to understand what the theory really means. Subsequently, she follows deep approach for her learning if the subject matter is really significant and interesting for her. This supports the view that students follow a variety of learning approaches, as stated in the literature (Ramsden 2003). What and how she learns depends on the topic/subject (Ramsden, 2003, pp.41-45). For her marketing classes she learns largely based on the L'Oreal BrandStorm competition. This is a competition arranged by L'Oreal among university students. The competition is about creating a new beauty product for the market, this includes the product itself, package design, branding, positioning, pricing, and the entire advertising campaign. This is a typical learning example via problem solving. While working on this case of L'Oreal, they launch a new product with new ideas on promotion. They are competing with another group of three University of Sydney students for this contest. The winning group then will compete against Melbourne universities. In the end, there will be only one group representing Australia for the final that will take place in Paris where they have to compete against the number one groups of many different counties. Last year, the winning group was from Switzerland, so they work with an extreme enthusiasm in terms of marketing to improve and find an outstanding marketing strategy for their own created products and marketing strategies. Sandy's conception of learning is the acquisition of facts, procedures or skills (learnt as theory in the classes) which she has to retain and utilize in practice (especially for the L'Oreal campaign). 
For Sandy learning is a very personal thing since she only learns things which interest her and which she will use further in her career. She is also an active learner, that is, she believes that learning occurs with actions and the learner's own efforts. Her approach and conception of learning is consistent with literature asserting that actionlearning principles should be aimed at developing the professional capability of students (Lizzio and Wilson, 2004). The whole L'Oreal campaign preparations have changed her life and her views completely. She has started to understand the meaning of every detail that was taught to her in the classes after having joined this competition. Klemp and McClelland (1986) affirm this perception of being capable under the higher notion of successful adaptation and adaptive flexibility in explaining professional capability.

We understand that Sandy takes a deep approach to learning. However, her learning approach may vary and fluctuate between surface and deep approach if the subject matter is not a selected one that she considers unimportant or not interesting, consistent with the literature (Ramsden 2003). She conceives learning as an understanding and increase in knowledge which she afterwards uses in practice. She considers herself as having understood something when she can apply what she has learnt into practice and possesses it as a skill afterwards. She believes that learning is an active process, and that one cannot learn in a passive way. This view of hers' is consistent with the notion that "learning is "caught not taught”"' (Gorard, Fevre, and Rees, G. 1999). The distinction between passive and active learning is that while the former gives the teacher an active role in transferring knowledge to students, the latter provides the teacher with a subtle role of indirectly fostering, enabling and catalyzing learning in the learners. This notion represents a Copernican shift from the former one (passive learning) into the latter one (active learning) in the context of a teacher-learner relationship (Ellerman, Denning and Hanna, 2001). Socrates is a classical prime example for the teacher in the active learner model. Due to his so-called "Socratic ignorance", he could not transmit or disseminate knowledge from the teacher to the student. Rather he invited his students to take an active role in thinking through a problem or question (case study) by opening a dialogue at hand and asking pointed questions to show the drawbacks of the traditional understanding and knowledge. Students find the answers from their own critical thinking and not from distributed information by others, that is, the teacher or the members of the society (Ellerman, Denning and Hanna, 2001).

The second selected student was Teresa. She also has both a deep and surface approach in her learning depending on the course. She feels a need to remember everything which she might get tested on which makes her a surface learner. However, she also continuously mentions that when she learns something she tries to find out deeply what it means and how it relates to what she already knew. She concurs that learning for her is an accumulation of knowledge. However, she also thinks that she is a passive learner and not an active one. Explicitly, she believes that learning is something which happens when you enter classes and read your readings but does not always require an additional effort. In comparison to Sandy, her approach is more of a surface one. Before the exams, she tries to memorize what the lecturer said or what was on the page. In fact, she defines herself as very successful and good at recalling which page of the book and which corner of the page was mentioning about the " $x$ " information even after one-time-reading. She explains it with the fact that she is a 'visual learner'; she takes photos of the pages in her mind. That is, as she explains, she is able to make pictures of these pages and reflects it into her brain. Afterwards, during an exam she is able to recall these pictures, whether the information was on the right-hand or left-hand page and even whether the information was on the top or bottom of the page. Yet, sometimes it happens, that she remembers where the information was placed on the books' page but cannot recall exactly what the information was really about to be able to give the correct answers to some questions. She said,

After the exam, when I do not need this information anymore to be recalled, I don't remember anything even though my marks are quite high.

She then added,

You know, our memory capabilities and memorizing function works amazingly, they never occupy too much space in our brains if they are not necessary anymore.

We had confusion and dilemma in categorizing Teresa's learning. Because even though she considers learning as an accumulation of knowledge, and mentions that when she learns something she tries to find out deeply 
what it means and how it relates to what she knew, her issues on memorizing and her decisions on what to learn makes her more a surface learner. She does not consider learning as a very personal thing. It is rather a compulsory thing that everyone has to follow in order to accomplish his/her goals.

There are some commitments, such as getting your diploma, finding a good job, promotion in your job..., and to be able to do well, succeed and achieve wherever you wish to go, you have to learn.

The third student, Chris, too, is a surface and deep approach learner. He generally tries to remember everything that he might get tested on. However, he also relates all new knowledge to his previously accumulated ones, because learning is for him "a buildup on knowledge". He states that learning is not about understanding all the time.

You learn how to ride a bike or how to drive a car, which does not mean you did understand all the functions involved with motors, gas, pedals etc. Yet, you still have learnt how to drive. You can even teach it to somebody else.

You know and have learnt that nights are followed by days and days are followed by nights. You have learned this. You don't have to know why this is happening. Even though you don't know the reason or how it happens, applies or functions you still have learnt that days are followed by nights and vice versa. You have learnt this fact. Whether you can explain the reason or how this happens, does not change that you know that nights are followed by days. This is what you have learned and this is your knowledge; you do not need to understand how.

Hence, we conclude that Chris's conception of learning does support the idea that learning is an increase in knowledge. However, as per Chris, one should be able to memorize things so that he can assume one has learnt something. One learns skills, procedures and utilize them in practice (such as biking, driving etc), and has to remember in order to be able to repeat these functions whenever necessary and in order to come to the same solution every time, even though this does not mean that learning is understanding. One learns, collects information, transforms it to knowledge and applies it. That is learning for Chris.

\section{RESULTS}

According to the students' feedback we have noticed that students' approaches to studying are affected by the peers' attitudes to studying (peers), student's special and personal interest in the topic or course (interest), teacher's ability to lecture joyfully and interestingly (performer on the scene) (Ramsden 2003), and topic's or course's usefulness for the student's future career (utility). These variables work sometimes as moderators, and now and then as partial mediators and even also as full mediators (Baron and Kenny, 1986) in my conceptual model.

Partial mediation occurs when there is a direct and indirect influence of the mediator between independent and dependent variables, whereas full mediation comes about when there is only a direct influence of the mediator between independent and dependent variables. Moderation is effective when there is a direct influence between the independent and dependent variables, yet, this effect can be maneuvered positively or negatively according to the direction, size, and density of the moderators (Baron and Kenny, 1986).

Hence, we can conclude that variables such as, peers' attitudes to studying, student's personal interest in the topic, teacher's performing ability, which would include the structure and organization of the course (Ramsden 2003, pp.41-45), and course's usefulness for the student's future career do also work both as mediators as well as moderators. This is due to the degree and intensity of students' approaches which can be correlated and equally influenced by the degree and intensity of these moderators. That is, for example, an increase in peers' attitude to studying, or teacher's performing ability may lead to an equal increase in deep approach or surface one.

In this project, after having reviewed the approaches and conceptions in the literature, we placed our interviews with the three students as distinct examples. Because of the many potential and existing mediator and moderator effects of many co-existing variables, we do not believe that one can distinguish which conception of learning a student is displaying precisely. Attempting to do that would lead to a confusion in terms of categorization 
since these groups depend merely on issues and circumstances as discussed before. One can even argue that personality traits and scales would lead to different categorization for the same circumstances etc. Therefore, instead of trying to accurately categorize the students we have interviewed, we have designed the conceptual model (Figure 1) which we develop as the result of the student's interviews to show the direct effects of conceptions on approaches.

Figure-Model 1

Direct Influences And Interactions Of Independent Variables Of Conceptions Of Learning On Dependant Variables Of Studying Approaches

Conceptions of learning

Studying approaches

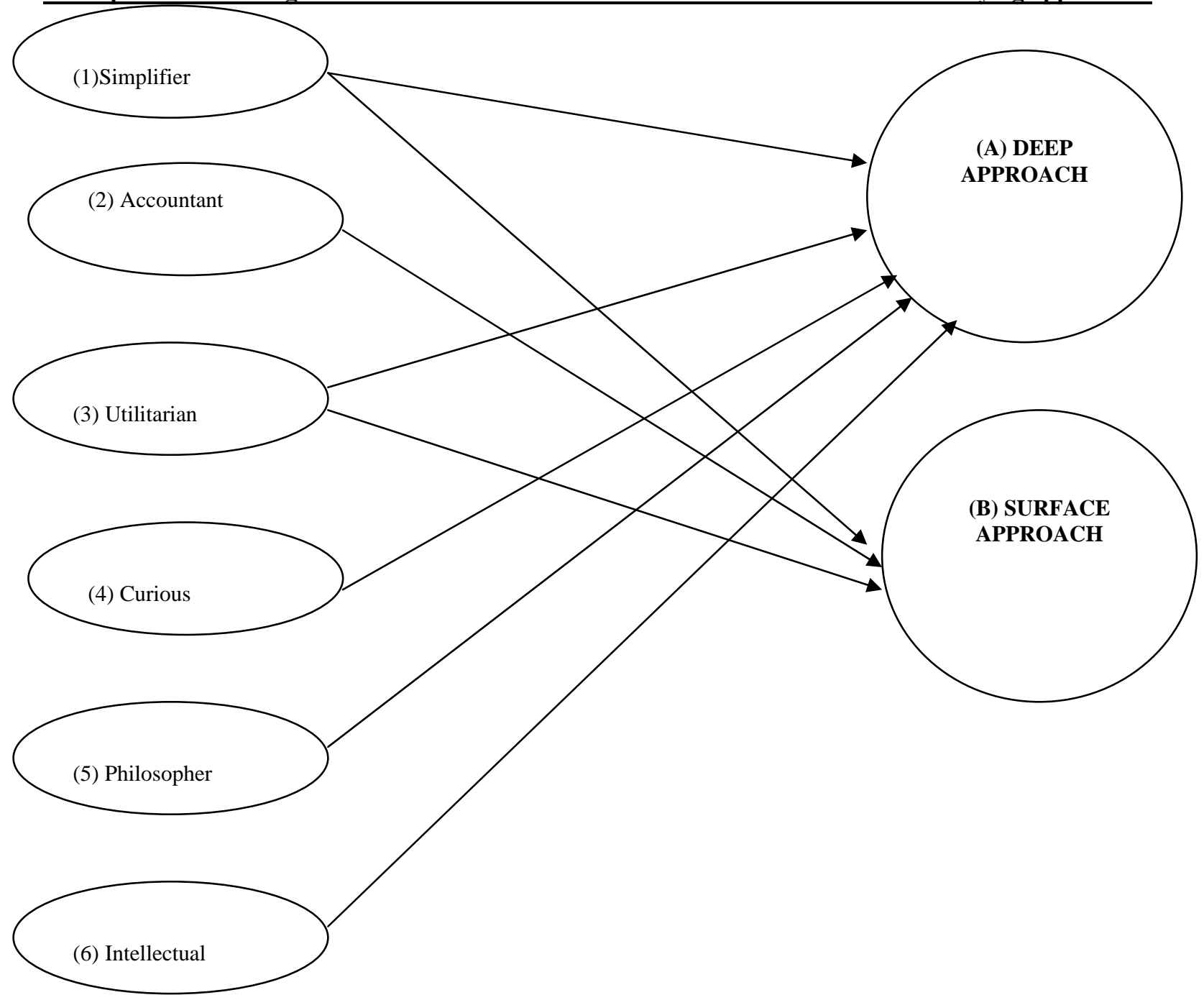

(1) Simplifier: Learning to increase knowledge; learning to gain common-knowledge (passive mode of learning)

(2) Accountant: (may also be called calculators): Learn to memorize, calculate the consequences and outcomes and use in necessities and desperate situations, such as to pass an exam, to find a job etc. (passive mode of learning)

(3) Utilitarian: Learn to use and apply the knowledge afterwards when necessary (passive mode of learning)

(4) Curious: Learn to understand and explain (active mode of learning)

(5) Philosopher: (may also be called Socrates): Learn to make sense of reality (active mode of learning)

(6) Intellectual: Learn to change as a person and effect and change his/her world around as well (active mode of learning) (Marton, Dall'Alba and Beaty 1993) 
The model drawn according to the students' interviews suggest that "simplifiers" and "utilitarians" use both, deep and surface approaches for their studying depending on the topic, and other mediators and moderators. While the "curious", "philosophers" and "intellectuals" usually have a deep approach to their studying, "accountants" have a merely surface approach to studying. This result indicates that being both simplifier and utilitarian directly affects both deep and surface approaches to studying. Being curious, philosophers or intellectuals directly influences a deep approach to studying, and being accountants openly affects and leads to surface approach to studying. Obviously, one can also argue that these affects would also work vice versa, that is, whether studying approaches would have any direct or indirect effects on learning conceptions. However, to be able to discuss this further and in more depth, we should have also explored the antecedents of approaches to studying deeply which would go beyond the scope of this paper.

\section{DISCUSSION}

Upon finishing the interviews and analysing the results, we did not stop the process of categorizing myself as a learner from my conceptions of learning. We fell into almost all categorisations depending on our tasks and individual responsibilities according to our professions. We were surprised to notice that we possess almost all the characteristics of the previous naming as "simplifiers", "utilitarian", "curious", "philosophic" "intellectual" and even "accountant" conceptions in different topics and even various days or times. The issue of 'time' not only affected us in the case of 'we as a learner' but also 'we as a teacher' consistent with the literature (Case and Gunstone, 2003, p.61). Our experiences as researchers who are employed and working full-time, with expectations of good teaching results, lead us to approach both learning for our research as well as our teachings at the university based on our own preferences, inclination to different topics, priorities, interests, and perceptions of time (Case and Gunstone, 2003, p.61).

\section{TEACHER'S PERCEPTIONS ON TEACHING AND STUDENT'S LEARNING}

This made us aware of the fact that the admirably well-explained autobiographical lens is affecting both our learning and teaching in an interactive way (Brookfield, 1995, pp.28-39). As a result, this notion made us become conscious of how our autobiography as a learner updates our teaching and how our autobiography as a teacher influences our learning. Consistent with our previous learning experiences we apply and will continue to apply selfgoverning research and problem solving based learning through an active learning environment (Lizzio and Wilson, 2004) with the assistance of discussions of case studies in businesses and independent research of student's own preference (Mann, 2001, p. 14 and 17). This approach to teaching and interactivity in the classroom is always well regarded by students as evidenced by high scores on student evaluations.

Indeed, we are very much impressed by Brookfield's four lenses concept (Brookfield, 1995, pp.28-39). Not only the autobiographical lens but also the theoretical perspective which has enlightened our knowledge on how the students learn, what they learn and under which circumstances they apply different conceptions and approaches. Baderin's explanation on assessment driving learning (2005, p.109) has let us to re-design and re-evaluate our assessments. Especially, the student interviews made us aware of the fact that even a very "curious", and "philosophic" student may easily drop to surface approach in line with the teacher's assessments.

Our interviews were extremely helpful in understanding the student lens. We teachers are too much influenced by our own autobiographical lens and fell easily into the well-known "false consensus effect" of social psychology assuming and exaggerating that others will think and behave as we do. "The false consensus effect refers to the tendency for people to overestimate the degree to which others agree with them. People readily guess their own opinions, beliefs and predilections as being more prevalent in the general public than they really are” (Dawes and Mulford 1996; Fields, James M., and Howard Schuman, 1976-77; Marks and Miller, 1987; Ross, Amabile, and Steinmetz, 1977; Ross, Greene, and House, 1977; Ross, Lepper and Hubbard, 1975). Brookfield's (1995) autobiographical lens reminds one on this notion of false consensus and how we teacher may easily make a wrong judgment that the students will learn in the same way as we did when we were a student. Therefore, the student lens part and the interviews were really very useful for us in defining approaches to studying and conceptions of learning, particularly after having finished the student interviews. 
And finally, the fourth lens, the peer lens, is certainly a good indicator for our teaching since we would be more subjective than objective towards our own teaching and learning. It is advisable to let a colleague from your own department or discipline peer-review your teaching. A colleagues' valuable insights will help improve your teaching and structure. One can first hesitate on the decision of whom to ask for the peer review process. Should it be somebody from your faculty and even within the department or discipline or somebody outside the faculty. After considering the pros and cons of both applications, we think having somebody from within the discipline due to the nature of the subjects and practices you pursue during the class.

\section{CONCLUSION}

In this study we did recast of the conceptions of learning literature to these qualities and attributes: simplifiers, accountants, utilitarians, curious, philosophers, and finally intellectuals to make sense of what conceptions of learning means. The classification of our student's conceptions and approaches to learning appears to be internally consistent. Sandy appears to engage actively when the subject is of interest to her and when she has an opportunity to demonstrate her learning through a real world application (i.e. L'Oreal). Teresa professes to want to understand, yet the strategies she employs are only consistent with a limited kind of understanding. The aspects of learning that are fore grounded for her seem to be committing things to memory. Teresa seems to have a tendency toward a surface approach. The challenge with Chris seems to be about a purpose for learning. Our analysis points to the inherent difficulties in the work of simple classification (the dynamic between different sets of variables is always a mediator here) - since learning is often messy and unbounded. It can often travel in very unpredictable ways. Our discussion of the factors affecting approaches to learning draws on the scholarly literature.

Brookfield's lenses (1995) are resonating -- particularly his description of the autobiographical lens. There is often a tendency to assume that those whom we teach are the learners we are, or the learners we want them to be rather than taking them for the learners they actually are. The beauty of adding the additional lenses of Brookfield's lenses is that they work to balance this out by providing us with different data upon which to base our decisions as teachers. Clearly, engaging in interviews with students has helped to clarify our own ideas about ourselves as a learner. That in itself is such a precious opportunity in a lot of ways.

\section{REFERENCES}

1. Akerlind, G. \& Trevitt, C. (1995) Enhancing learning through technology: When students resist the change. In J.M. Pearce \& A. Ellis (Eds) Learning with Technology. (pp. 1-9) The Science Multimedia Teaching Unit, Melbourne.

2. Baderin, M.A. (2005). Towards improving students' attendance and quality of undergraduate tutorials: a case study in law. Teaching in Higher Education, 10 (1), 99-116.

3. Baron, R.M. \& Kenny, D.A. (1986). The Moderator-Mediator Variable distinction in Social Psychological Research: Conceptual, Strategic, and Statistical Considerations, Journal of Personality and Social Psychology, 51-6, 1173-82.

4. $\quad$ Brookfield, S. (1995). Becoming a Critically Reflective Teacher. San Francisco: Jossey-Bass.

5. Case, J. \& Gunstone, R. (2003). Going deeper than deep and surface approaches: a study of students' perceptions of time. Teaching in Higher Education, 8 (1), 55-69.

6. Dawes, R.M. \& Mulford, M. (1996). The false consensus effect and overconfidence: Flaws in judgment, or flaws in how we study judgment? Organizational Behavior and Human Decision Processes 65: 201-11.

7. Ellerman, D., Denning, S., \& Hanna N. (2001), Active learning and development assistance, Journal of Knowledge Management, 5, 2, 173-9.

8. $\quad$ Fields, James M. \& Howard Schuman, (1976-77) Public Beliefs about the Beliefs of the Public, Public Opinion Quarterly, 40, 427-48.

9. Gorard, S., Fevre, R., \& Rees, G. (1999), The apparent decline of informal learning, Oxford Review of Education, 25, 437-54.

10. Klemp, G. O. \& McClelland, D.C. (1986), What characterizes intelligent functioning among senior managers? In R. J. Steinberg \& R.K. Wagner (Eds) Practical Intelligence: Nature and Origins of Competence in the Everyday Worlds. (Cambridge, Cambridge University Press.) 
11. Lizzio, Alf \& Keitha Wilson (2004), Action learning in higher education: An investigation of its potential to develop professional capability, Studies in Higher Education, 29 (4), 469-88.

12. Mann, S.J. (2001). Alternative perspectives on the student experience: alienation and engagement. Studies in Higher Education, 26 (1), 7-19.

13. Marks, G. \& Miller, N. (1987). Ten years of research on the false consensus effect: an empirical and theoretical review. Psychological Bulletin, 102, 72-90.

14. Marton, F., Dall’Alba, G., \& Beaty, E. (1993). Conceptions of learning. International Journal of Educational Research, 19, 277-300.

15. Marton, F. \& Säljö, R. (1976). On qualitative differences in learning: Outcome and process. British Journal of Educational Psychology, 46, 4-11.

16. Marton, F., Watkins, D., \& Tang, T. (1995, August 26-31). Discontinuities and continuities in the experience of learning: An interview study of high-school students in Hong Kong. Paper presented at the 6th European Conference for Research on Learning and Instruction, Nijmegen, Netherlands.

17. Marton, F., Watkins, D., \& Tang, C. (1997). Discontinuities and continuities in the experience of learning: an interview study of high-school students in Hong Kong. Learning and Instruction, 7, $21-48$.

18. Marton, F., Wen, Q., \& Nagle, A. (1996). Views on learning in different cultures. Comparing patterns in China and Uruguay. Anales de Psicologia. 12 (2), 123-32.

19. Ramsden, P. (1992). Learning to teach in higher education, Routledge: London.

20. Ramsden, P. (2003). Learning to Teach in Higher Education. $2^{\text {nd }}$ ed. London: Routledge.

21. Ross, L, Amabile, T. M., \& Steinmetz, J. L.(1977) Social roles, social control and biases in social perception, Journal of Personality and Social Psychology, 35, 485-494.

22. Ross, L., Greene, D., \& House, P. (1977). The false consensus effect: an egocentric bias in social perception and attribution processes. Journal of Experimental Social Psychology 13, 279-301.

23. Ross, L., Lepper, M. R., \& Hubbard, M. (1975) Perseverance in self-perception and social perception: Biased attributional processes in the debriefing paradigm, Journal of Personality and Social Psychology, 32, 880-92.

\section{NOTES}




\section{NOTES}

